Document downloaded from:

http://hdl.handle.net/10251/117533

This paper must be cited as:

Montanes, N.; Quiles-Carrillo, L.; Ferrándiz Bou, S.; Fenollar, O.; Boronat, T. (2019). Effects of Lignocellulosic Fillers from Waste Thyme on Melt Flow Behavior and Processability of Wood Plastic Composites (WPC) with Biobased Poly(ethylene) by Injection Molding. Journal of Polymers and the Environment. https://doi.org/10.1007/s10924-019-01388-0

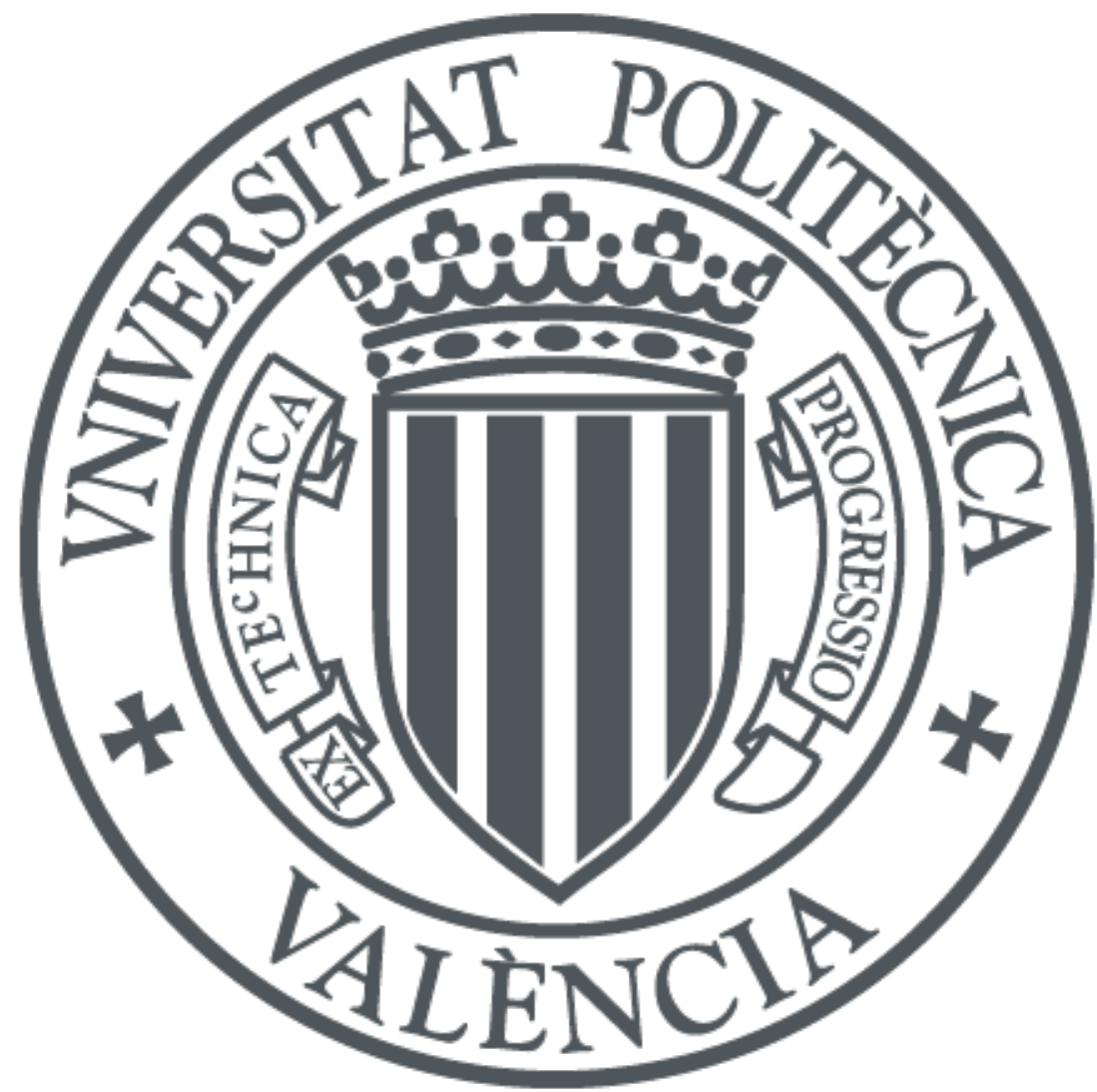

The final publication is available at

https://doi.org/10.1007/s10924-019-01388-0

Copyright Springer-Verlag

Additional Information 


\title{
"Effects of lignocellulosic fillers from waste thyme on melt flow behavior and processability of wood plastic composites (WPC) with biobased poly(ethylene) by injection molding"
}

\author{
N. Montanes, L. Quiles-Carrillo, S. Ferrandiz, O. Fenollar, T. Boronat* \\ Institute of Materials Technology (ITM) \\ Universitat Politècnica de València (UPV) \\ Plaza Ferrándiz y Carbonell, s/n \\ 03801 Alcoy - SPAIN
}

* Correspondence to: Teodomiro Boronat

E-mail: tboronat@dimm.upv.es

Tel.: +34966528468 


\section{Abstract}

Wood-like plastic composites were manufactured with a thermoplastic matrix polymer from renewable resources, i.e. high-density poly(ethylene) from bioethanol and a lignocellulosic filler obtained as a byproduct of the industrial distillation of thyme. The potential manufacturing of these composites by injection molding was studied. For this purpose, an in depth study of the effects of the lignocellulosic loading (comprised between $10-50 \mathrm{wt} . \%$ ) on the rheological properties of these composites was carried out by using capillary rheometry and model fitting with the Cross-WLF rheological model. In addition, a side by side comparison of the experimental results and those obtained by simulations with MoldFlow ${ }^{\circledR}$ was provided. In addition, the values of the pressure in the cavity and in the sprue were measured and collected by two selectively mounted pressure sensors and the results were compared with those predicted by MoldFlow ${ }^{\circledR}$ with the inputs provided by the Cross-WLF fitting model. The results showed a remarkable increase in viscosity with increasing lignocellulosic filler content, which has a negative effect on overall processability. This phenomenon specifically intense at low shear rates. However, this phenomenon could be potentially minimized using high shear rates because of the shear thinning effect of pseudoplastic fluids. Both the experimental and simulated results suggest the need of higher pressures to fill the cavity with these WPC, specifically for those with high filler content of up to $50 \mathrm{wt} . \%$. The results of the study indicate that melt viscosity is highly linked to the cavity pressure which is the dominant factor determining the quality of the final product in plastic injection molding. 
Keywords: Natural fibers; Rheological properties; Process Simulation; Injection molding; Thyme 


\section{Introduction}

Industrial byproducts have become a serious environmental problem in recent years due to the enactment of more severe government legislation regulating their disposal as a consequence of increasing social concern on environmental issues and sustainable development. Food and brewing industries generate large amounts of wastes which are usually deposited in controlled landfills or incinerated to obtain the residual energy. Most of these residues could be potentially upgraded by using them as fillers in wood plastic composites (WPCs). Thus, the environmental impact is reduced from two points of view: on one hand, a new life is given to the residue and on the other hand, less raw materials are needed for the manufacture of plastic parts. The WPC industry has experienced a remarkable rise in the last years. Today it is possible to find WPCs new technical applications in the automotive industry (interior parts, acoustic isolation panels, etc.) as well as in the building sector (decking, fencing, furniture, etc.) due to their woodlike appearance and competitive price. Most of these industrial WPC products contain high lignocellulosic filler content and the typical manufacturing processes are extrusion and hot-press molding [1, 2]. Many WPC parts contain sawdust or other wood derived particles as main filler which could potentially be substituted by lignocellulosic industrial byproducts. Therefore, the conversion of these byproducts into new, useful, and valueadded products has become a necessity. For this reason, research in this field has been intensified in the last years in a remarkable way. Fortunati et al.[3] studied the extraction of lignocellulosic materials from waste products. They also evaluated their potential as 
reinforcement component in environmentally friendly composites. Another study from Huang et al.[4] used coffee husks in order to reinforce polyethylene composites.

Thyme is an aromatic plant, typical of temperate regions with a growing position in the world market and with high economic importance. Thyme includes more than 300 different species worldwide. Thymus moroderi is the typical of the southeast of Spain. Thyme is commonly used as seasoning due to its pharmacological and aromatic properties as Ruiz-Navajas et al.[5] described. Díaz-Garcia et al.[6] studied the potential of thyme in the food industry as odorant and natural antioxidant due to the presence of anthocyanins (E-163). Sukhwinder[7] reported the use of thyme in the manufacture of packaging due to its antioxidant and antimicrobial properties. One increasing use of thyme is the distillation of the flower and the peduncle with ethanol to obtain the corresponding herb liquor. After distillation a big amount of thyme waste is generated. There is a recent trend in using lignocellulosic fillers in order to provide wood like appearance such Cicala[8] reported.

Injection molding is widely used processing technique because it is an economic technology for producing high volume of complex plastic articles as Tang at al. [9] pointed. The processing conditions[10] and the material characteristics[11] are the key parameters in injection molding. The WPCs industry will have to face a key challenge in the following years, which is the use of conventional injection molding equipment to obtain high filler content WPCs with complex shapes. Injection molding of polymer-filled materials is very challenging due to the noticeable different flow behavior regarding neat polymers. Wan Abdul Rahman et al.[12] suggested that the lack of knowledge about the 
material characteristics in polymer composites is responsible for incomplete part fillings and other defects. Furthermore, today it is common to use simulation tools before processing the plastic part in order to optimize the processing parameters such Andrzejewski et al.[13] reported. So, it is essential to characterize the processability of a particular material previously to obtain an accurate simulation of the manufacture process. Although the trial and error methodology is widely used in the plastics industry, it is not the best option to reduce manufacturing cycles. A viscosity function (model) is required to simulate the injection molding process since the melt behavior of the polymer is a key parameter in the filling stage. Koszkul and Nabialek [14] studied the suitability of several viscosity models to simulate the filling stage during the injection molding process. Mazzanti and Mollica[15] successfully fitted the experimental rheology measurements of a WPC to the Carreau-Yasuda model in order to analyze the flow characteristics for further processing. It is important to study the filling stage in order to yield a good-quality product thus ensuring the melted polymer fills the mold cavity without air entrapments, flow lines, jetting or any other defects.

The main aim of this research is to assess the potential of conventional injection molding technique to manufacture wood plastic composite parts with a biobased high density poly(ethylene) matrix and a high lignocellulosic filler from industrial thyme wastes. In particular, the effect of the lignocellulosic filler loading on viscosity, mold filling stage of WPC and, globally on processability is studied. This work also explores the potential and reliability of simulation tools to predict and validate the rheological behavior of high lignocellulosic content polymer systems. 


\section{Experimental}

\subsection{Materials}

High renewable content Wood Plastic Composites were manufactured with a biobased poly(ethylene) and thyme wastes. High-density polyethylene (HDPE) grade SHA7260 was supplied in pellet form by Braskem (São Paulo, Brazil). This commercial HDPE grade is obtained from sugarcane and possesses a melt flow rate (MFR) of $20 \mathrm{~g} / 10$ min, a density of $0.955 \mathrm{~g} \mathrm{~cm}^{-3}$ and its biobased content is higher than $95 \%$ as indicated in the technical datasheet. Thyme was provided by a local distillery, since it is obtained after the distillation of the flower of thyme for the manufacture of a highly valued local liquor. Due to the hydrophilic nature of natural fibers, poly(ethylene-co-glycidil methacrylate) (PEGM) supplied by Sigma-Aldrich (Sigma-Aldrich Química, S.A., Madrid, Spain) was used as compatibilizer to increase polymer-filler interaction [16].

Prior to composite manufacturing, the thyme was dried in an air circulating oven mod. 2001245 Digiheat-TFT from J.P. Selecta S.A. (Barcelona, Spain) at $40^{\circ} \mathrm{C}$ for 48 hours to remove residual moisture. After this stage, it was milled and sieved with a $25 \mu \mathrm{m}$ mesh using an ultra-centrifugal Mill ZM 200 provided by Retsch (Düsseldorf, Germany).

Five different formulations were prepared with weight percentages of thyme comprised in the 10-50 wt. \% range, while the compatibilizer content was set to $10 \mathrm{wt} . \%$ of filler. All three components were previously mechanically mixed in a zipped bag to pre-homogenize and then compounded in a twin screw co-rotating extruder from DUPRA S.L. (Castalla, Spain), screw diameter: $16 \mathrm{~mm}, \mathrm{~L} / \mathrm{D}$ ratio of 24 at a rotating speed of $40 \mathrm{rpm}$. The temperature profile from the hopper to the die was set to $165^{\circ} \mathrm{C}$ (feeding), 
$170{ }^{\circ} \mathrm{C}, 170^{\circ} \mathrm{C}, 175^{\circ} \mathrm{C}, 175^{\circ} \mathrm{C}$, and $180^{\circ} \mathrm{C}$ (die) and after cooling, the obtained compound was pelletized.

\subsection{Rheological characterization}

The rheological characterization was conducted on a capillary rheometer model Rheoflixer from Thermo Haake (Karlsruhe, Germany). Three different tungsten carbide nozzles were used with L/D ratio of 10, 20 and 30 and a diameter of $1 \mathrm{~mm}$. The shear rate varied between 100 and 10,000 s-1. This wide shear rate range was selected to match different processing conditions as Shenoy and Saini [17] recommended. A Haake pressure transducer 0-1400 bar Quality class I up to $400{ }^{\circ} \mathrm{C}$ was used for data acquisition. Composite pellets were placed inside the barrel and after a residence time of 5 minutes it was forced down into the capillary with a plunger. The melt was extruded through the capillary at seven preset shear rates $\left(100,200,500,1000,2000,5000,10000 \mathrm{~s}^{-1}\right)$ and the corresponding pressure values were collected. The measured pressure drop always approached a stable level within time scale. The measurements were carried out at two different temperatures, $190^{\circ} \mathrm{C}$ and $210^{\circ} \mathrm{C}$ as this temperature range is commonly used for HDPE. Real shear stress and shear rate were obtained applying the Bagley [18] and Rabinowitsch [19] corrections. All tests were carried out as indicated in ISO-11443.

\subsection{Thermal characterization}


Dynamic mechanical thermal analysis (DMTA) was used to obtain the glass transition temperature $\left(\mathrm{T}_{\mathrm{g}}\right)$ of the obtained composites using an oscillatory rheometer AR-G2 from TA Instruments (New Castle, USA) equipped with a torsion accessory for

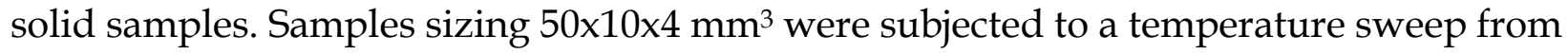
$-150{ }^{\circ} \mathrm{C}$ up to $110^{\circ} \mathrm{C}$ at a heating rate of $2^{\circ} \mathrm{C}$ min $^{-1}$ under a controlled strain $(\gamma)$ of $0.1 \%$ at a frequency of $1 \mathrm{~Hz}$.

\subsection{Rheological model fit}

Viscosity plays a key role in injection molding as shear-flow influences strongly the polymer melt flow during the cavity filling stage. Simulation of this stage was done using Moldflow ${ }^{\circledR}$. This software requires a previous fitting of the rheological measurements to the Cross-WLF model in order to obtain an accurate simulation of the flow behavior. Cross-WLF model is preferred for numerical simulation. Cross[20] determined that the shear viscosity of the material in a very wide range of temperatures and shear rates, followed this expression.

$\eta(\dot{\gamma}, T, P)=\frac{\eta_{0}(T, P)}{1+\left(\frac{\eta_{0}(T, P) \cdot \dot{\gamma}}{\tau^{*}}\right)^{(1-n)}}$

Where: $\eta_{0}[\mathrm{~Pa} s]$, is the viscosity of the material under zero-shear-rate conditions. $\tau^{*}[\mathrm{~Pa}]$, is a constant of the model that indicates the minimum shear stress rate that 
promotes a change to a pseudoplastic behavior. $n[-]$, is a constant of the model which symbolizes the pseudoplastic behavior slope of the material as: (1-n). The viscosity of the material under zero-shear-rate conditions was determined by the Williams-Landel-Ferry (WLF)[21] expression.

$\eta_{0}(T, P)=D_{1} \cdot e^{\left(\frac{-A_{1} \cdot\left(T-D_{2}-D_{3} \cdot P\right)}{\tilde{A}_{2}+T-D_{2}}\right)}$

Where: $\mathrm{D}_{1}[\mathrm{~Pa} \cdot \mathrm{s}]$, is a constant that registers the viscosity of the material, under zero-shear-rate conditions, at specific temperature and pressure conditions, i.e. glass transition temperature $\left(\mathrm{T}_{\mathrm{g}}\right)$ and atmospheric pressure respectively. $A_{1}[-]$, is a constant of the model that stands for the temperature dependence of the glass transition temperature under zero-shear-rate conditions. $T[K]$, is the melting temperature of the polymer. $D_{2}[K]$, is a constant which registers the glass transition temperature of the material at atmospheric pressure. $D_{3}[\mathrm{~K} / \mathrm{Pa}]$, is a constant that symbolizes the variation of the glass transition temperature of the material, according to the pressure. $P[b a r]$ is the pressure at the capillary inlet. $\tilde{A}_{2}[K]$, is a constant parameter that depends on the type of material.

\subsection{Methodology for determination of specific heat capacity $\left(c_{p}\right)$}

The $c_{p}$ values of the WPCs were determined by differential scanning calorimetry (DSC) by means of a Mettler-Toledo 821 DSC calorimeter (Schwarzenbach, Switzerland) according to ISO 11357-4:2014. Three heat flow measurements by DSC runs were carried 
out in order to determine the experimental specific heat of each sample: blank (empty aluminum pan), reference material and the sample itself. $\alpha$-alumina with a purity of 99.9\% was used as the calibration material. Specimens and $\alpha$-alumina were encapsulated in standard sealed $40 \mu \mathrm{L}$ aluminum crucibles. Each test was repeated at least twice to ensure reproducibility. A three step heating program in oxygen atmosphere, was applied for the measurements: (i) an isothermal stage at $30^{\circ} \mathrm{C}$ for $5 \mathrm{~min}$; (ii) dynamic heating from $30{ }^{\circ} \mathrm{C}$ up to $250{ }^{\circ} \mathrm{C}$ at a heating rate of $10^{\circ} \mathrm{C} \mathrm{min}-1$ and (iii) isothermal stage at $250{ }^{\circ} \mathrm{C}$ for 5 min. All the samples were previously dried in an air circulating oven at $40^{\circ} \mathrm{C}$ for 48 hours in order to remove any residual moisture.

The specific heat capacity $\left(c_{p}\right)$ of each sample was obtained applying the next formula proposed by the abovementioned standard,

$$
c_{p}^{s p}=c_{p}^{c a l} \frac{m^{c a l} \cdot\left(P_{\text {specimen run }}-P_{\text {blank run }}\right)}{m^{s p} \cdot\left(P_{\text {calibration run }}-P_{\text {blank run }}\right)}
$$

Where $c_{p}$ is the heat capacity; $\mathrm{m}$ is the mass; $\mathrm{P}$ stands for the heat flow rate; superscripts "cal" and "sp" represent calibration and specimen, respectively. The heat capacity of the calibration material was obtained from the standard.

\subsection{Sample manufacturing and simulation}

An experimental mold was specifically built and mounted on a Mateu \& Solé model Meteor 270/75 injection molding machine. The mold had two cavities with two 
different gates in each part: one film gate in one end and one-tab gate in the other. The mold was equipped with several valves in order to select the desired cavity and gate. The selected cavity for this study was a flat and thin rectangle of $160 \times 60 \times 2 \mathrm{~mm}^{3}$ which allows to study the effect of viscosity on the injection filling stage. Two Kistler 6157BA pressure sensors were set in the mold. The first one was placed at the bottom of the sprue in order to measure the real injection pressure and another at the entrance of the cavity which determines the injection pressure in the part. Figure 1 shows the geometry used in the study and the location of the pressure sensors.

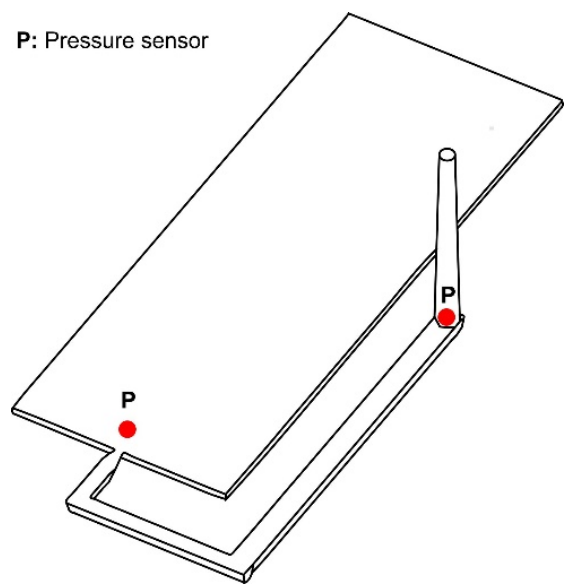

Figure 1. Geometry of injected part and sensor locations.

Experimental procedures were also simulated using the computer-aided Autodesk Moldflow ${ }^{\circledR}$ Insight software (2016 version). Simulation results were used to determine the best injection conditions and to validate the rheological model.

\subsection{Methodology of injection molding and simulation}


Once the specific heat capacity and the viscosity parameters were obtained they were used as entry parameters into the Moldflow ${ }^{\circledR}$ software in order to simulate the injection process. Injection simulation is a powerful tool which allows to determine the optimum processing conditions. It predicts the approximate values of the injection parameters to be introduced in the real injection machine by avoiding trial and error procedures.

Two different tests, both at $200{ }^{\circ} \mathrm{C}$, were carried out in order to study the filling stage of the injection of WPCs with varying thyme filler loading into the mold cavity. On one hand, a proper injection was done with $1 \mathrm{~s}$ filling time, once the $90 \%$ of the part was filled it switched to the packing pressure in order to fill the remaining $10 \%$ and it was kept until solidification to prevent shrinkage. On the other hand, a nonstandard injection procedure was used. This was defined by the lowest filling rate that the injection machine needs to completely fill the cavity in the filling stage using raw HDPE, with no additional packing pressure. Finally, the plastic part was ejected once it was cooled. The same procedure was applied to all five WPCs formulations. The mold was preheated and maintained at $50{ }^{\circ} \mathrm{C}$ for all tests. Both procedures were carried out both in simulation and in injection molding.

\section{Results and discussion}

\subsection{Effect of the filler loading on the dependent parameters of the Cross-WLF model}

The effect of thyme filler on the viscosity and processing parameters of HDPE/thyme WPCs was studied through the analysis of the rheological properties of 
composites in the melt state, and also through the study and comparison of injection simulations and real injection measurements. Rheological measurements are highly sensitive to the filler content as shown in Figure 2a, where it is depicted the melt viscosity values of raw HDPE and HDPE/thyme WPCs measured at $190^{\circ} \mathrm{C}$ as a function of the shear rate. All the herein developed WPCs show a much higher viscosity than raw HDPE, but the shear rate dependency does not vary in a great extent. The viscosity of the composites raises progressively with increasing thyme filler content. This is mainly because the lignocellulosic filler does not allow the polymer to flow normally and restricts the mobility of the chain segments in the flow direction. Similar findings have been reported by Mohanty and Nayak[22] for sisal fiber-reinforced PE composites. Carneiro and Maia[23] stated that fibers show large reinforcement capacities at low shear rates due to fiber-fiber interactions produced by feeble structures made up by agglomerates of nonaligned fibers.

a)

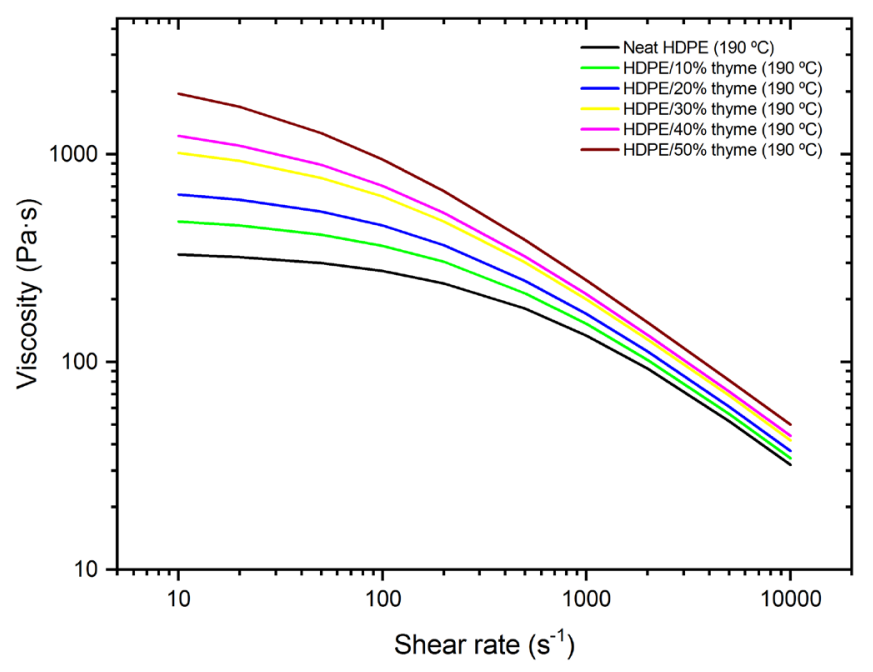




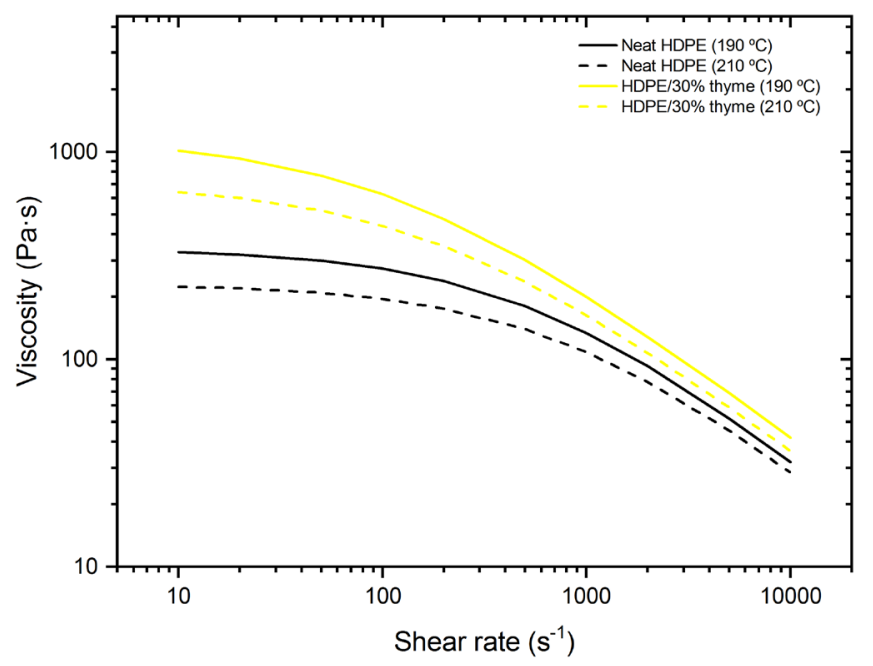

Figure 2. Capillary rheology of HDPE/thyme composites, a) variation of apparent shear viscosity as a function of the thyme filler content, b) variation of apparent shear viscosity in terms of temperature (2 compositions).

All the studied compositions present a pseudoplastic behavior over the whole shear rate range, but it is much more pronounced at high shear rates. This performance at high shear rates could be associated to the decrease of fiber-to-fiber collision as a consequence of the fiber alignment along the flow direction as Crowson et al.[24] reported. There are similar studies such Goldsmith's[25] who observed radial migration of the filler particles towards capillary axis during shear flow. Thereby in a filled-polymer system, the material located near the capillary walls is almost fiber-free. So, at high shear rates all composites show similar viscosity values independently of the filler amount. The effect of the thyme filler is more pronounced at low shear rates; the effect of the filler content on viscosity is less intense with increasing shear rates as a consequence of shear thinning. The viscosity at low shear rates such $10 \mathrm{~s}^{-1}$ increased from values near $300 \mathrm{~Pa}$ up to values near $2,000 \mathrm{~Pa}$ s at $190{ }^{\circ} \mathrm{C}$ as the filler content increased from 0 to $50 \mathrm{wt} \%$. 
There are several factors hindering the melt flow of the HDPE/thyme WPCs such as surface area, filler porosity and presence of thyme aggregates, so the viscosity rises as the thyme content increases. Therefore, the melt processing of high filler content compounds would show difficulties in processes working with low shear rates. However, processes operating at high shear rates, such as injection molding, show less processing problems as a consequence of the shear thinning effect.

Figure $2 \mathrm{~b}$ also confirms the strong temperature dependence of the shear viscosity of raw HDPE and its composites with thyme as it shown in the comparison of the curves of neat $\mathrm{HDPE}$ and $\mathrm{HDPE} / 30 \%$ at $190^{\circ} \mathrm{C}$ and $210^{\circ} \mathrm{C}$. The melt viscosity of raw $\mathrm{HDPE}$ and composites decreases as the temperature increases. This is due to weaker intermolecular interactions and also as a consequence of the accelerated molecular motion produced by greater free volume and a decrease of entanglement density as WLF determined. The influence of temperature on viscosity is a key factor since it deeply influences the processing conditions and the quality of the final product.

In order to determine the seven parameters featured by the Cross-WLF model, Reig et al.[26] proposed to divide all seven parameters into two main groups in terms of their dependency on the physical properties of the material. The first set of parameters (independent parameters) consists of three parameters that only depend on the material, so they remain constant during the study. DMTA tests for all the studied concentrations were carried out in order to determine the glass transition temperature but variations between them were considered negligible, so a single temperature was used in this study. 


$$
\begin{aligned}
& \widetilde{A}_{2}=51.6 \mathrm{~K} \\
& D_{2}=T_{g}=-125^{\circ} \mathrm{C}=148.15 \mathrm{~K} \\
& D_{3}=\frac{\partial T_{g}}{\partial p}=0 \mathrm{~K} / \mathrm{Pa}
\end{aligned}
$$

The second set of parameters (four) are the dependent parameters of the CrossWLF model which must be calculated for all the compositions. $\mathrm{D}_{1}$ is not considered to be a relevant parameter since the process conditions differ from the glass transition temperature, zero-shear-stress and atmospheric pressure conditions. Therefore, the $\mathrm{D}_{1}$ evolution with the filler content is not analyzed. However, it is important to determine its value to calculate the viscosity under zero-shear-rate conditions $\left(\eta_{0}\right)$ by applying the WLF expression. PTC Mathcad Prime ${ }^{\circledR} 3.0$ was used to calculate the dependent parameters applying chi-square iterations using data from the three dies and the two temperatures tested in the capillary rheometer. The values obtained the four dependent parameters and for the zero shear rate viscosity are presented in Table 1.

\begin{tabular}{|c|c|c|c|c|c|}
\hline $\begin{array}{c}\text { wt.\% thyme } \\
\text { filler }\end{array}$ & $\mathbf{D}_{\mathbf{1}}[-]$ & $\mathbf{A}_{\mathbf{1}}[\mathbf{P a} \mathbf{~ s ]}$ & $\boldsymbol{\tau}[\mathbf{P a}]$ & $\mathbf{n}[-]$ & $\begin{array}{c}\boldsymbol{\eta}_{\mathbf{0}}\left[\mathbf{2 1 0}{ }^{\mathbf{}} \mathbf{C}\right] \\
{[\mathbf{P a} \mathbf{~ s}]}\end{array}$ \\
\hline $\mathbf{0}$ & $4.021 \mathrm{E}+22$ & 53.79 & $1.981 \mathrm{E}+05$ & 0.202 & 340.86 \\
\hline $\mathbf{1 0}$ & $4.286 \mathrm{E}+19$ & 54.37 & $1.706 \mathrm{E}+05$ & 0.229 & 503.82 \\
\hline $\mathbf{2 0}$ & $2.601 \mathrm{E}+24$ & 57.81 & $1.569 \mathrm{E}+05$ & 0.243 & 697.53 \\
\hline $\mathbf{3 0}$ & $9.592 \mathrm{E}+28$ & 69.44 & $1.396 \mathrm{E}+05$ & 0.257 & 1172.7 \\
\hline $\mathbf{4 0}$ & $4.675 \mathrm{E}+31$ & 76.38 & $1.311 \mathrm{E}+05$ & 0.263 & 1468.0 \\
\hline $\mathbf{5 0}$ & $2.479 \mathrm{E}+37$ & 90.89 & $1.189 \mathrm{E}+05$ & 0.269 & 2610.0 \\
\hline
\end{tabular}

Table 1. Comparison of the Cross-WLF dependent parameters of HDPE/thyme varying the thyme filler content

The effect of wt \% of thyme on shear viscosity can be analyzed in depth with the study of the Cross-WLF dependent parameters and the viscosity under zero-shear-rate 
conditions $\left(\eta_{0}\right)$. $\mathrm{D}_{1}$ has not been analyzed since it denotes the viscosity at glass-transition temperature and zero-shear-stress conditions; such settings differ to the ones applied in this study and to industrial conditions. $\mathrm{D}_{1}$ has been determined in order to calculate $\eta_{0}$ using the WLF expression.

The viscosity sensitivity to temperature is offered by the $A_{1}$ parameter. This is an important parameter when the manufacturing processes proceeds at high temperatures such as typical temperatures of the injection molding process. High values of $\mathrm{A}_{1}$ assume a high influence of the temperature resulting in reductions of viscosity and therefore processability improvements. There is a pronounced upward trend when the thyme filler content increases, so it is possible to conclude that the increase in the filler content enhanced the sensitiveness to temperature. This phenomenon is shown in the viscosity curves of Figure 2 at different temperatures; the increasing distance between curves for the same composition at different temperatures with increasing filler content is shown.

Despite zero-shear-rate viscosity is calculated using $\mathrm{A}_{1}$ and $\mathrm{D}_{1}$, it is considered a consistent parameter because it is measured at a real processing temperature $\left(190^{\circ} \mathrm{C}\right) . \eta_{0}$ is an important parameter for the cooling and packing stages of the injection molding process where the material practically does not flow. It is well established that the addition of thyme into the polymer matrix increases the $\eta_{0}$ of the melt. From Table 1, it can be assumed that the increase in the zero-shear-rate viscosity depends on the filler content, and also from other parameters such as particle size and distribution and shape of the filler as Părpăriță et al.[27] suggested. The presence of the lignocellulosic filler causes resistance against the flow and increases the viscosity of the melt WPCs. 
The transition between the Newtonian and the shear thinning regimes is characterized in the Cross model. Such transition is defined by the $\tau$ parameter. $\tau$ shows the minimum shear rate over which the material shows a pseudoplastic behavior. It can be seen from the data in Table 1 that $\tau$ decreases as the filler content increases. So, the Newtonian regime is shortened and the region where the shear rate does not affect the viscosity is subsequently reduced. Therefore, the advancement of shear thinning behavior slightly counteracts the increase in viscosity caused by the filler content. That fact has a positive effect on the processability of materials at medium shear rates values.

The slope of the shear thinning region in the polymer melt viscosity curve was calculated by the value of (1-n), with $\mathrm{n}$ ranging from 0 to 1 . The melt behaves as a Newtonian fluid for $n$ values close to 1 . From a manufacturing point of view, it is interesting to handle low $n$ values which lead to obtain low viscosities at the same shear rate. Therefore, the analyzed polymer filled composites present a more Newtonian behavior with increasing filler content, which causes a dilution of the shear thinning effect. 


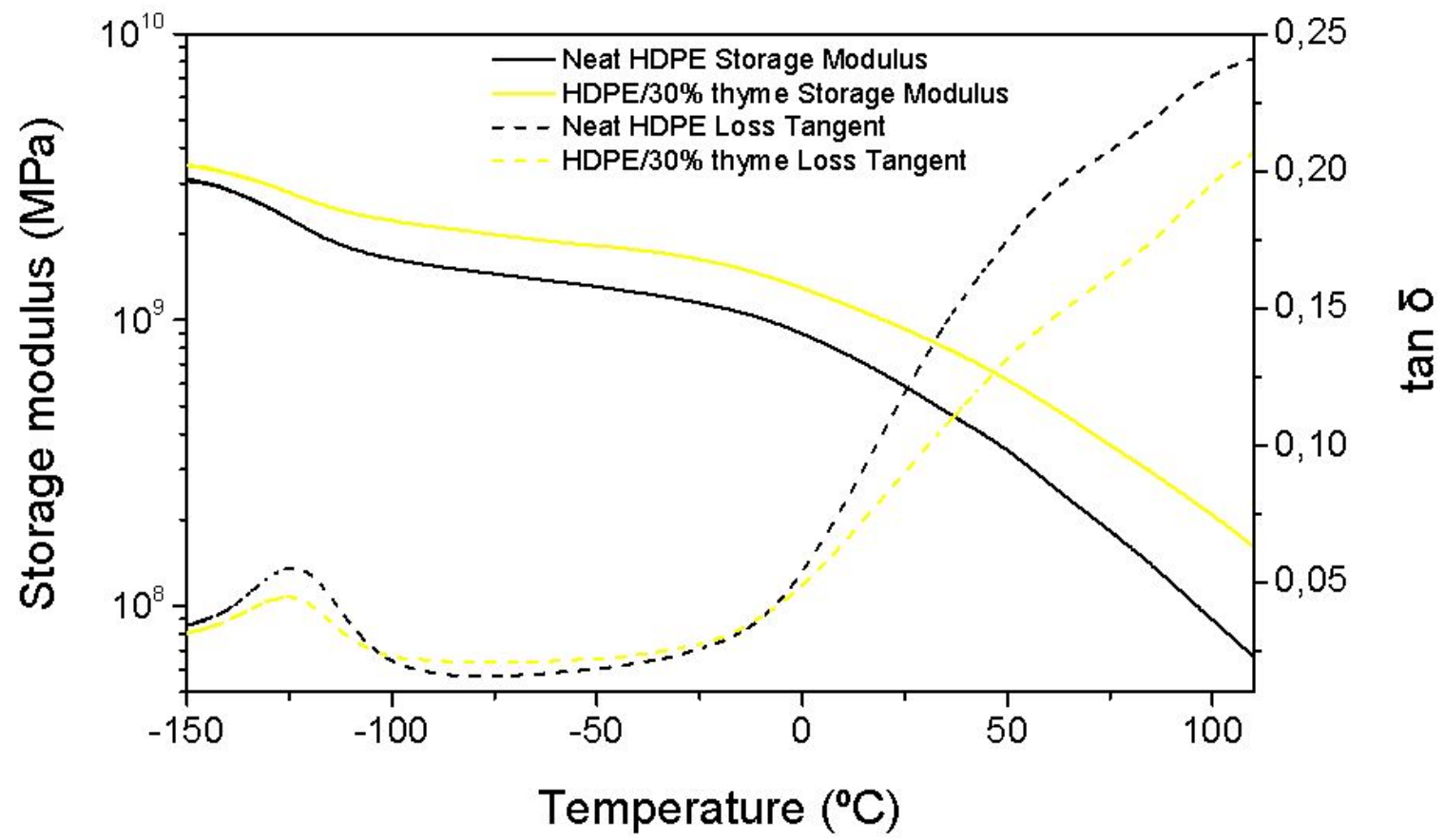

Figure 3. Plot evolution of the phase angle $(\delta)$ and storage modulus $\left(G^{\prime}\right)$ in terms of temperature for net HDPE and HDPE/30\% thyme composite.

A DMTA test was carried out in order to determine the $\mathrm{D}_{2}$ parameter from the Cross-WLF expression. $\mathrm{D}_{2}$ represents the glass transition temperature $\left(\mathrm{T}_{\mathrm{g}}\right)$ of the analyzed materials. Figure 3 shows a plot comparison of the DMTA curves corresponding to raw HDPE and a HDPE/thyme WPCs with 30 wt.\% thyme. The storage modulus $\left(G^{\prime}\right)$ increases by the addition of a lignocellulosic filler, which indicates that the filler stiffens the composite. It is also worthy to note that the storage modulus decreases as temperature increases due to the softening of materials. The softening is more pronounced in the raw material compared to composites since the filler does not soften with temperature. The analysis of the damping factor $(\tan \delta)$ shows a peak located at $-125^{\circ} \mathrm{C}$ which reveals the glass transition temperature, $T_{\mathrm{g}}$. $\mathrm{T}_{\mathrm{g}}$ has the same value for both raw HDPE and its WPCs 
with varying thyme filler content thus indicating that filler does not affect the glass transition temperature of HDPE.

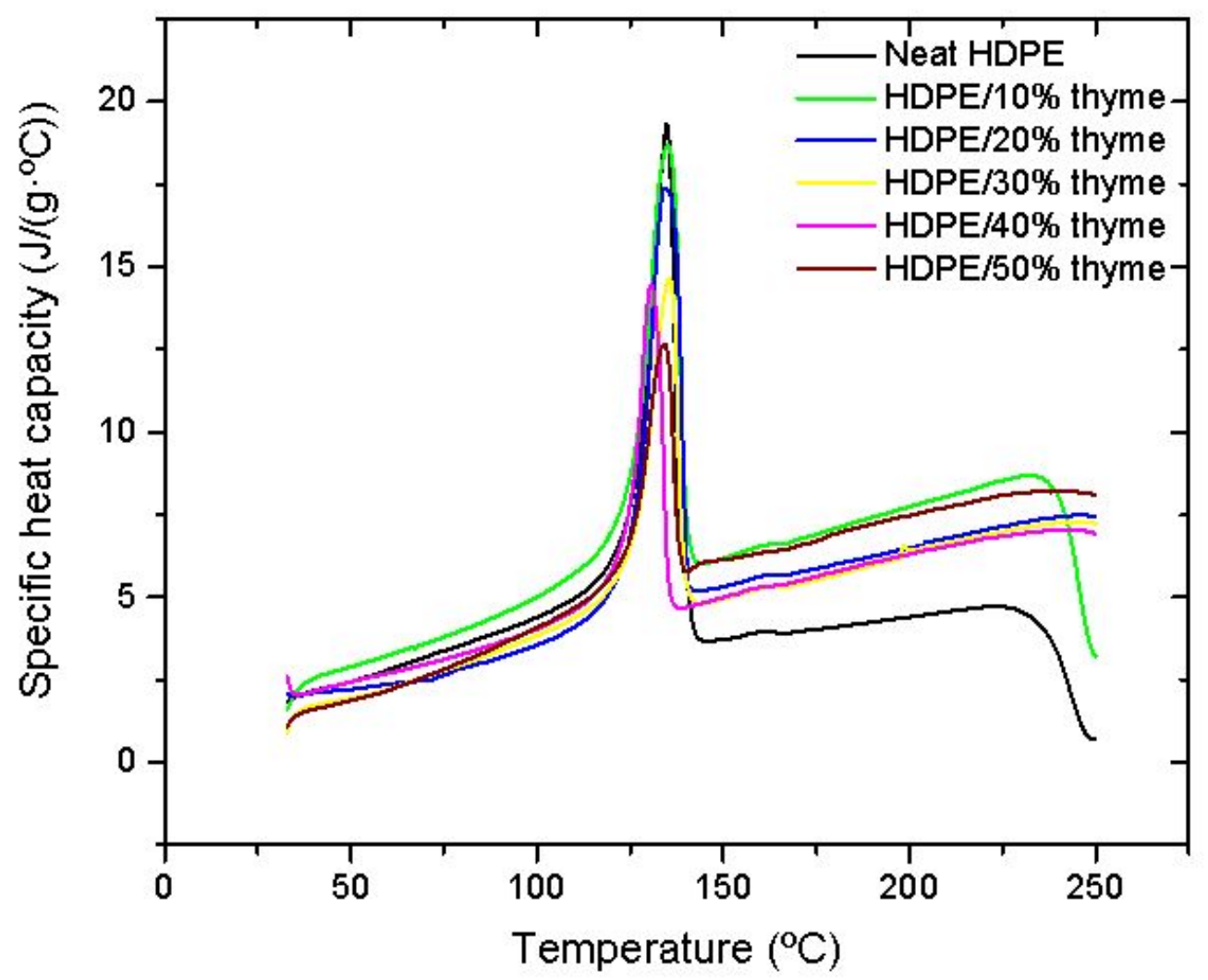

Figure 4. Plot evolution of specific heat capacity in terms of temperature of HDPE/thyme composites.

\subsection{Effect of the filler loading on the heat capacity of HDPE/thyme WPCs}

Specific heat of the studied materials was determined for further simulation of the heat transfer processes. It can be seen from curves in Figure 4 that the specific heat $\left(c_{p}\right)$ of HDPE/thyme WPCs can be divided into three different stages. In the first stage the specimens are in solid state and there is an almost proportional increment of $c_{p}$ with 
temperature. Then the second stage involves a drastic increase in the $c_{p}$ and then it drops back when the melting process ends. During the melting process, the abrupt increase in the specific heat is caused by the presence of two overlapping endothermic processes. Firstly, the ordinary heating process in which, the material needs to absorb heat to increase its temperature. This heat allows increased polymer chain motions and vibrations. Secondly, it is important to take into account that poly(ethylene) is a semicrystalline polymer. Once certain temperature is reached, the packed crystalline structure needs additional heat supply (enthalpy) to break this ordered and packed structure and promote the melting process thus allowing polymer chains to flow. The temperature range for the melting process of all HDPE/thyme WPCs is almost the same, but the peak temperature (which is representative for the maximum melting rate) varies depending on the thyme filler content. The specific heat in this second stage decreases as the amount of filler increases due to the dilution effect that the lignocellulosic filler provides. Finally, in the third stage, specimens are already in the melt state and the $c_{p}$ increases proportionally with temperature, as expected, with no addition abrupt change. 


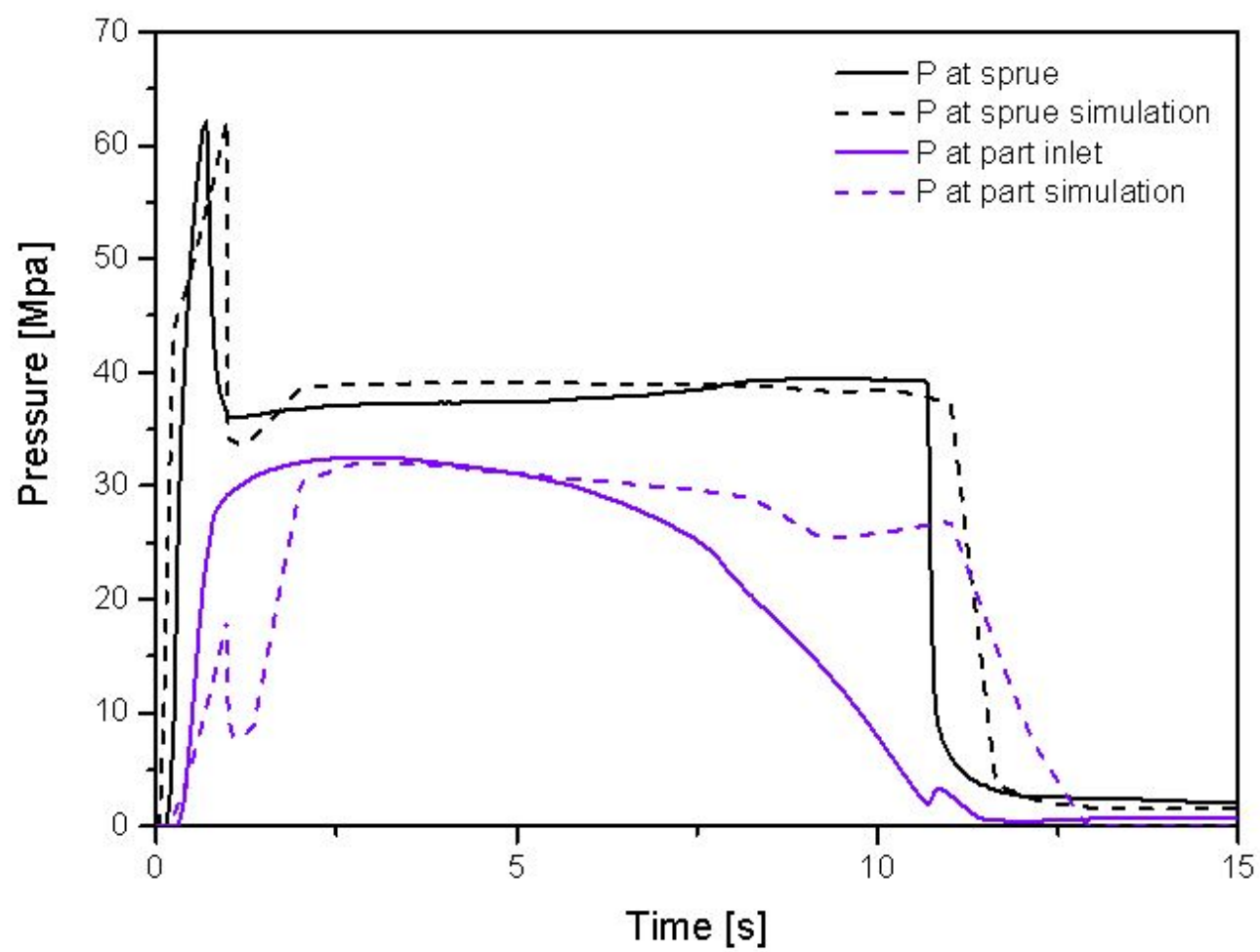

Figure 5. Plot evolution of pressure at sprue and at part inlet comparing real and simulation values of net HDPE at $200{ }^{\circ} \mathrm{C}$.

\subsection{Simulation of injection molding of HDPE/thyme WPCs with different thyme filler loading}

To obtain an accurate simulation of the injection molding process, it is necessary to use some entry parameters in the simulation software. These parameters were obtained by using the Cross-WLF applied to the rheological parameters and the specific heat capacity of all HDPE/thyme WPCs as described in the previous sections. The rheological parameters are necessary to simulate the melt flow while the specific heat is needed to simulate the heating and cooling processes of the samples. Figure 5 shows the pressure evolution of raw HDPE subjected to a standard injection molding procedure at different mold locations, both for experimental measurements and simulation values. The cavity 
pressure trajectory during injection filling stage is highly dependent on other processing variables. Hence, it is a good indicator to assess high quality injected plastic parts. Moreover, its reproducibility is vital for producing plastic parts with tight tolerances as Kurt at al.[28] pointed out. As a consequence of the increasing distance of the measuring point from the flow path, the pressure values at the inlet part show lower values than those registered at the bottom of the sprue. A great similarity between the experimental results and those obtained by software simulation is observed, especially for data at the bottom of the sprue. Pressure curves in the part location present some differences. The curve of pressure obtained by simulation shows a peak produced by the filling of the cavity. However, this peak does not appear in the experimental measurements. As a result of the presence of this peak, the measurements are displaced right from experimental. 


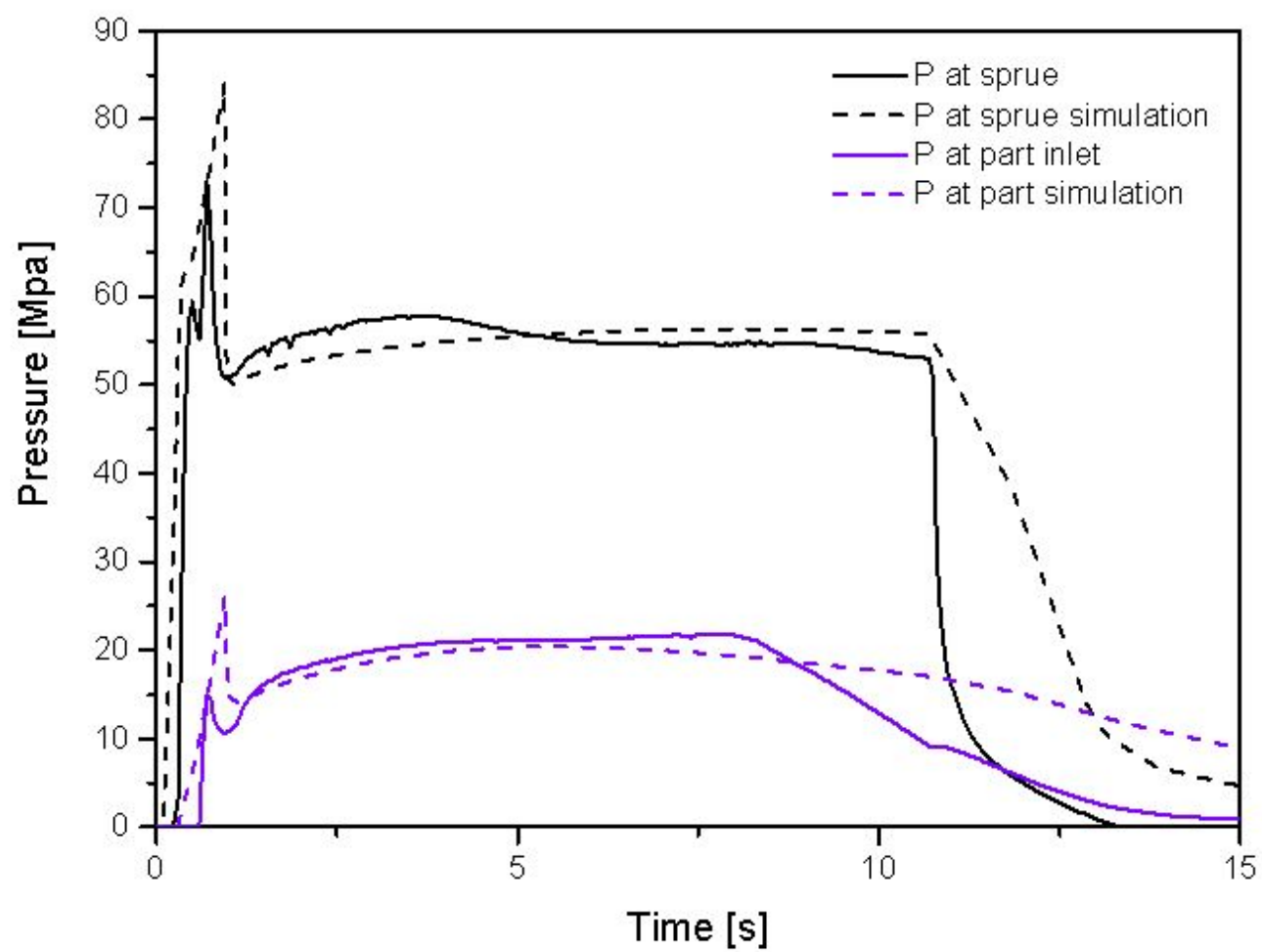

Figure 6. Plot evolution of pressure at sprue and at part inlet comparing real and simulation values of HDPE $/ 40 \%$ thyme at $200{ }^{\circ} \mathrm{C}$.

The predicted and measured pressure profiles versus filling time for the HDPE/thyme WPCs with 40 wt. \% thyme are shown in Figure 6. The packing pressure shows a remarkable increase compared to raw HDPE since the filled material is more viscous and the cavity was not completely filled. Simulation approaches in the two studied locations are fairly accurate. The geometry of the curves is similar; the most remarkable difference is in the initial filling spout. Simulation shows a higher peak than the experimental values. This is more pronounced on the curves of the inlet part. However, the curves are equalized after the filling spout. There are also some differences in the cooling stage where the simulation pressure values decrease more slowly. 
If curves in Figure 5 and Figure 6 are compared it can be concluded that the sensor located at the bottom of the sprue provides higher pressure values. This could be related to the fact that the machine is set to fill the cavity in $1 \mathrm{~s}$ and, as the melt composite has a higher viscosity, then the required pressure is higher. In contrast, the comparison of the values in the sensor located at the part inlet offers the opposite behavior. Higher pressure values are obtained for neat HDPE with regard to HDPE/thyme composites. This effect is also produced by higher viscosity that HDPE/thyme composites possess, since the applied pressure is worse transmitted through all the material disposed in the feed channels.

The validation of the rheological model was confirmed with a second injection test procedure. First the cavity was filled with virgin HDPE at the minimum possible speed without subsequent compaction. Then the different HDPE/thyme composites were injected maintaining these test conditions. This is not a usual procedure and is not suitable for obtaining a proper injected plastic part nor for achieve high productivity but it is very useful to validate the previous results. Both experimental and software simulated results for this test are shown in Figure 7. Raw HDPE plastic part is completely filled but it shows some defects as jetting produced by the low-speed filling procedure and warpage due to the lack of packing pressure. The same injection procedure test was applied to HDPE/thyme composites and, as expected, these processing conditions, although they can completely fill the cavity with neat HDPE without addition compaction pressure, are not capable to completely fill the cavity due to the increase in viscosity that increasing lignocellulosic fillers provides. The total filled volume decreases 
with increasing filler content. This confirms that the increasing filler amount leads to a remarkable increase in viscosity and therefore the melt flow is restricted. As per the results, the experimental data are supported by software simulation results which are quite accurate and validate the rheological results.

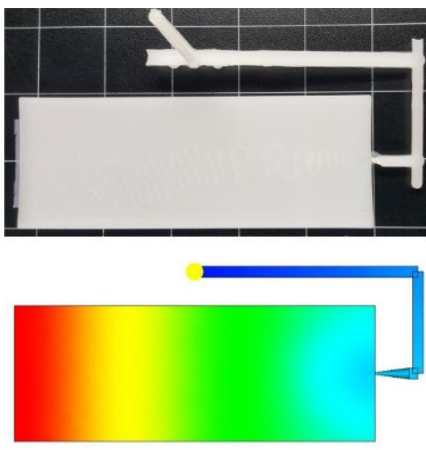

Neat HDPE
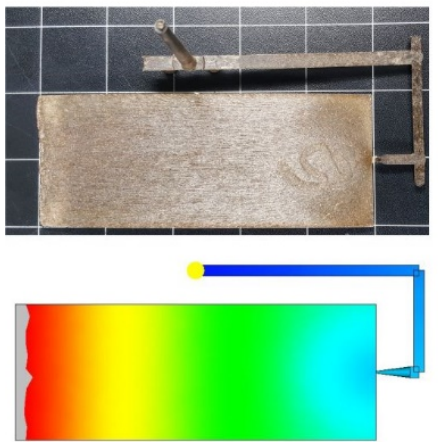

HDPE $/ 10 \%$ thyme
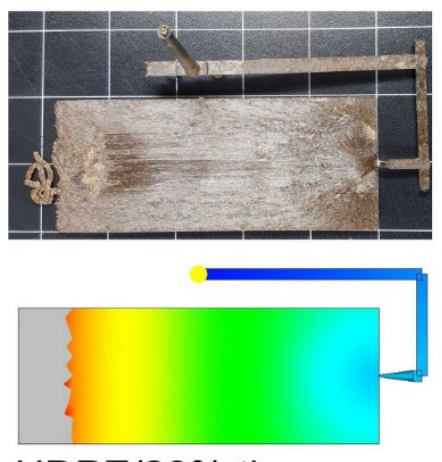

HDPE/20\% thyme
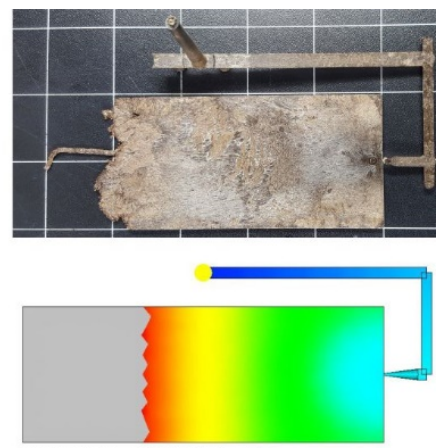

HDPE $/ 30 \%$ thyme
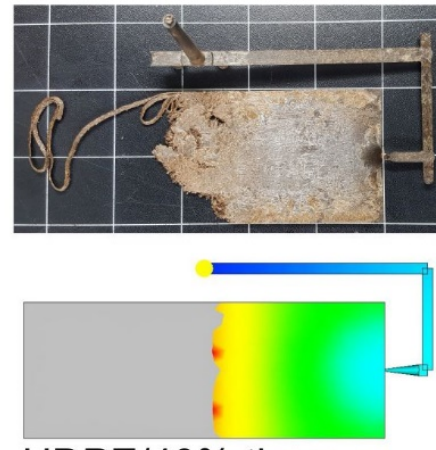

HDPE $/ 40 \%$ thyme
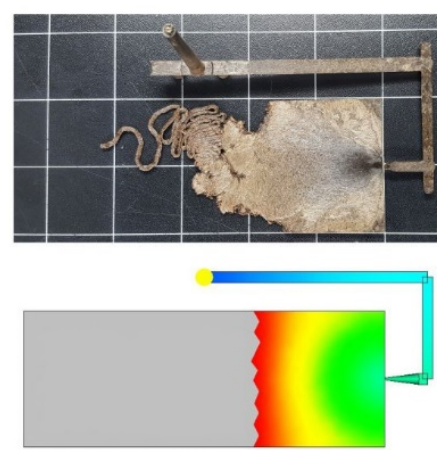

HDPE $/ 50 \%$ thyme

Figure 7. Results of injected and simulated parts applying a test procedure with no compaction. 


\section{Conclusions}

The main goal of this research was to assess the potential of conventional injection molding to manufacture high lignocellulosic filler polymer composites, up to $50 \mathrm{wt} . \%$ as alternative manufacturing techniques to extrusion and hot-press molding to obtain WPCs with high filler content. High environmentally friendly WPCs were manufactured with a biobased high density poly(ethylene) and a lignocellulosic filler from industrial thyme wastes with different loads up to $50 \mathrm{wt} . \%$. The influence the filler on the viscosity of the developed WPCs and, subsequently on their processability by injection molding was assessed. In order to reach this goal a complete rheological study of the HDPE/thyme composite system served as base study to validate experimental data with software simulated results by using the Cross-WLF model parameters as entry values in Moldflow@ software. The following conclusions can be drawn:

- The rheological behavior is highly sensitive to the wt $\%$ filler content.

- The viscosity of HDPE/ thyme WPCs raises progressively with increasing amount of TM specially at low shear rates. This increase is faded out at high shear rates due to the shear thinning effect of pseudoplastic fluids.

- The increasing amount of thyme slightly shifts the shear thinning behavior to lower shear rates, with the subsequent positive effect on the overall processability of the materials at medium shear rates values

- HDPE/thyme WPCs with high filler load are not suitable to be processed with low shear rate manufacturing processes such rotational molding. 
- As expected, viscosity is also temperature dependent. Lower viscosity values were obtained with increasing temperature, but excessively high temperatures cannot be used to avoid thermal degradation of the lignocellulosic filler.

- As the filler content increases the amount of heat needed to melt the composite decreases, due to the diluting effect that the filler provides, which reduces energy costs.

- HDPE/thyme WPCs require higher pressures to completely fill the part cavity as a consequence of higher melt viscosity. Those high viscosities harm the pressure transmission through the feed channels. 


\section{ACKNOWLEDGMENTS}

This research was supported by the Ministry of Economy and Competitiveness MINECO through the grant number MAT2014-59242-C2-1-R. Authors also wish to thank "Licores Sinc, S.A." for kindly supplying the thyme wastes. 


\section{References}

1. Koivuranta, E., et al., Improved durability of lignocellulose-polypropylene composites manufactured using twin-screw extrusion. Composites Part A: Applied Science and Manufacturing, 2017. 101: p. 265-272.

2. Tufan, M., et al., Technological and thermal properties of thermoplastic composites filled with heat-treated alder wood. BioResources, 2016. 11(2): p. 3153-3164.

3. Fortunati, E., et al., Extraction of Lignocellulosic Materials From Waste Products, in Multifunctional Polymeric Nanocomposites Based on Cellulosic Reinforcements, D. Puglia, E. Fortunati, and J.M. Kenny, Editors. 2016, Elsevier: Oxford. p. 408.

4. Huang, L., et al., Sustainable use of coffee husks for reinforcing polyethylene composites. Journal of Polymers and the Environment, 2016: p. 1-11.

5. Ruiz-Navajas, Y., et al., In Vitro Antioxidant and Antifungal Properties of Essential Oils Obtained from Aromatic Herbs Endemic to the Southeast of Spain. Journal of Food Protection, 2013. 76(7): p. 1218-1225.

6. Díaz-García, M.C., et al., Production of an anthocyanin-rich food colourant from Thymus moroderi and its application in foods. Journal of the Science of Food and Agriculture, 2015. 95(6): p. 1283-1293.

7. Bhullar, S.K., B. Kaya, and M.B.-G. Jun, Development of Bioactive Packaging Structure Using Melt Electrospinning. Journal of Polymers and the Environment, 2015. 23(3): p. 416-423.

8. Cicala, G., et al., Investigation on Structure and Thermomechanical Processing of Biobased Polymer Blends. Journal of Polymers and the Environment, 2016: p. 1-9.

9. Tang, S.H., et al., The use of Taguchi method in the design of plastic injection mould for reducing warpage. Journal of Materials Processing Technology, 2007. 182(1-3): p. 418-426.

10. García-Manrique, J.A., et al., A numerical simulation of woven/anionic polyamide 6 composite part manufacturing using structural reactive injection moulding process. Journal of Thermoplastic Composite Materials, 2014: p. 0892705714530746.

11. Haworth, B., et al., Thermoplastic composite beam structures from mixtures of recycled HDPE and rubber crumb for acoustic energy absorption. Journal of Thermoplastic Composite Materials, 2016: p. 0892705716681836.

12. Wan Abdul Rahman, W.A., L.T. Sin, and A.R. Rahmat, Injection moulding simulation analysis of natural fiber composite window frame. Journal of Materials Processing Technology, 2008. 197(1-3): p. 22-30.

13. Andrzejewski, J., et al., The influence of processing conditions on the mechanical properties and structure of poly (ethylene terephthalate) self-reinforced composites. Journal of Thermoplastic Composite Materials, 2014: p. 0892705714563117.

14. Koszkul, J. and J. Nabialek, Viscosity models in simulation of the filling stage of the injection molding process. Journal of Materials Processing Technology, 2004. 157-158: p. 183-187.

15. Mazzanti, V. and F. Mollica, In-Process Measurements of Flow Characteristics of Wood Plastic Composites. Journal of Polymers and the Environment, 2016: p. 1-7.

16. Montanes, N., et al., Processing and Characterization of Environmentally Friendly Composites from Biobased Polyethylene and Natural Fillers from Thyme Herbs. Journal of Polymers and the Environment, 2017.

17. Shenoy, A. and D. Saini, Rheological models for unified curves for simplified design calculations in polymer processing. Rheologica acta, 1984. 23(4): p. 368-377.

18. Bagley, E., End corrections in the capillary flow of polyethylene. Journal of Applied Physics, 1957. 28(5): p. 624-627.

19. Rabinowitsch, B., Über die Viskosität und Elastizität von Solen. Z. Physik. Chem., 1929. A 145: p. 1-26.

20. Cross, M.M., Rheology of Non-Newtonian Fluids - a New Flow Equation for Pseudoplastic Systems. Journal of Colloid Science, 1965. 20(5): p. 417-\&.

21. Williams, M.L., R.F. Landel, and J.D. Ferry, Mechanical Properties of Substances of High Molecular Weight .19. the Temperature Dependence of Relaxation Mechanisms in Amorphous Polymers and Other Glass-Forming Liquids. Journal of the American Chemical Society, 1955. 77(14): p. 3701-3707.

22. Mohanty, S. and S.K. Nayak, Rheological characterization of HDPE/sisal fiber composites. Polymer Engineering \& Science, 2007. 47(10): p. 1634-1642.

23. Carneiro, O.S. and J.M. Maia, Rheological behavior of (short) carbon fiber/thermoplastic composites. Part I: The influence of fiber type, processing conditions and level of incorporation. Polymer Composites, 2000. 21(6): p. 960-969. 
24. Crowson, R.J., M.J. Folkes, and P.F. Bright, Rheology of short glass fiber-reinforced thermoplastics and its application to injection molding I. Fiber motion and viscosity measurement. Polymer Engineering and Science, 1980. 20(14): p. 925-933.

25. Goldsmith, H., Rheology Theory and Application, , S.G. Mason, Editor. 1967, Academic Press. p. 85.

26. Reig, M.J., V.J. Segui, and J.D. Zamanillo, Rheological behavior modeling of recycled ABS/PC blends applied to injection molding process. Journal of Polymer Engineering, 2005. 25(5): p. 435-457.

27. Părpăriţă, E., et al., Structure-morphology-mechanical properties relationship of some polypropylene/lignocellulosic composites. Materials \& Design, 2014. 56: p. 763-772.

28. Kurt, M., et al., Experimental investigation of plastic injection molding: Assessment of the effects of cavity pressure and mold temperature on the quality of the final products. Materials \& Design, 2009. 30(8): p. 3217-3224. 


\section{Table captions}

Table 1. Cross-WLF dependent parameters of bioPE-TM composites. 


\section{Figure legends}

Figure 1. Geometry of injected part and sensor locations.

Figure 2. Capillary rheology of HDPE/thyme composites, a) variation of apparent shear viscosity as a function of the thyme filler content, b) variation of apparent shear viscosity in terms of temperature ( 2 compositions).

Figure 3. Plot evolution of the phase angle $(\delta)$ and storage modulus $\left(G^{\prime}\right)$ in terms of temperature for net HDPE and HDPE/30\% thyme composite.

Figure 4. Plot evolution of specific heat capacity in terms of temperature of HDPE/thyme composites.

Figure 5. Plot evolution of pressure at sprue and at part inlet comparing real and simulation values of net $\mathrm{HDPE}$ at $200^{\circ} \mathrm{C}$.

Figure 6. Plot evolution of pressure at sprue and at part inlet comparing real and simulation values of $\mathrm{HDPE} / 40 \%$ thyme at $200{ }^{\circ} \mathrm{C}$.

Figure 7. Results of injected and simulated parts applying a test procedure with no compaction. 